\title{
The effect of humidity and temperature on visual outcomes after myopic corneal laser refractive surgery
}

This article was published in the following Dove Press journal:

Clinical Ophthalmology

4 November 2016

Number of times this article has been viewed

\section{Christopher T Hood' \\ Roni M Shtein' \\ Daniel Veldheer ${ }^{1,2}$ \\ Munira Hussain' \\ Leslie M Niziol' \\ David C Musch',3 \\ Shahzad I Mian'}

'Department of Ophthalmology and Visual Sciences, University of Michigan W.K. Kellogg Eye Center,Ann Arbor, MI, 2Department of Anesthesiology, Medical College of Wisconsin, Milwaukee, WI, ${ }^{3}$ Department of Epidemiology, University of Michigan, Ann Arbor, MI, USA
Correspondence: Shahzad I Mian Department of Ophthalmology and Visual Sciences, University of Michigan W.K. Kellogg Eye Center, 1000 Wall St, Ann Arbor, MI 48I05, USA

Tel +l 7347635506

Fax +I 7349362340

Email smian@med.umich.edu
Objective: To determine whether procedure room environmental conditions are associated with outcomes after myopic laser in situ keratomileusis (LASIK) or laser-assisted keratomileusis (LASEK).

Design: Retrospective chart review.

Participants: Eight hundred sixty-three eyes of 458 consecutive patients at a university-based academic practice.

Methods: We reviewed the medical records of consecutive patients who underwent LASIK or LASEK over a 3-year period. Linear mixed regression models were used to investigate the association of laser room temperature and humidity with the outcomes of visual acuity and postoperative manifest spherical equivalent refraction. Repeated measures logistic regression models were used for the outcomes of diffuse lamellar keratitis (DLK) and need for enhancement surgery.

Results: Subjects were on an average 38.6 years old at the time of surgery (standard deviation $[\mathrm{SD}]=10.3$ ) and the average spherical equivalent refraction of eyes was 3.8 diopters ( $\mathrm{SD}=2.03$ ). Regression models did not reveal a significant association between temperature and uncorrected distance visual acuity (UDVA) or corrected distance visual acuity (CDVA), or between humidity and UDVA ( $P>0.05$ for all). However, increased humidity was associated with a small but statistically significant improvement in CDVA after LASIK at 1 day, 1 month, 3 months, and 1 year postoperatively ( $P<0.05$ for all). There was no significant association between temperature and humidity and the need for enhancement, the incidence of DLK, or postoperative manifest refraction.

Conclusion: While increased laser room humidity was consistently associated with small improvements in CDVA after myopic LASIK over time, variations in room temperature and humidity were not associated with UDVA, the need for enhancement, the incidence of DLK, or refraction after myopic LASIK or LASEK.

Keywords: LASIK, LASEK, refractive surgery, temperature, humidity

\section{Introduction}

Perioperative variables impacting outcomes after laser refractive surgery have been extensively evaluated. Though excellent uncorrected visual acuity is often obtained after excimer laser refractive surgery, ${ }^{1,2}$ past studies have demonstrated that factors including surgeon, technique, degree of myopia, patient age, corneal curvature, and ablation size, among others, can affect visual outcomes. ${ }^{2-5}$ While patient and surgeon variables are largely not modifiable, operating room environmental factors such as temperature and humidity can potentially be optimized. Mathematical modeling 
suggests that environmental thermohygrometric factors may influence the outcome of refractive surgery by absorbing laser fluence, ${ }^{6}$ but the clinical significance of variations in temperature and humidity remains unclear. Some authors have concluded that elevated procedure room temperature and humidity result in worse outcomes, ${ }^{7,8}$ while others have reported no difference. ${ }^{9}$ More recently, a retrospective series of over 200,000 eyes demonstrated no clinically significant effect of procedure room temperature and humidity on refractive outcomes, ${ }^{10}$ while another study with over 41,000 eyes concluded that lower operating room temperature was associated with more retreatments. ${ }^{11}$ To address this ambiguity in the literature, we designed a retrospective study to determine whether procedure room temperature and humidity are associated with postoperative outcomes after myopic excimer laser vision correction. Specifically, we evaluated temperature and humidity for associations with visual acuity, enhancement rate, the incidence of diffuse lamellar keratitis (DLK), and postoperative manifest refraction.

\section{Methods}

After Institutional Review Board approval was granted by the University of Michigan, we performed a retrospective review of the medical records of consecutive patients who had undergone laser in situ keratomileusis (LASIK) or laser-assisted keratomileusis (LASEK) for simple myopia and compound myopic astigmatism over a 3-year period at the W.K. Kellogg Eye Center, University of Michigan, Ann Arbor, MI, USA. The Institutional Review Board of the University of Michigan did not require written informed consent be obtained from the participants, as this was a retrospective study, and all data was anonymous. Only eyes targeted for emmetropia were included. Eyes were excluded if they had previous refractive surgery or developed postoperative striae, flap displacement, epithelial ingrowth, or corneal haze.

Preoperatively, all patients underwent a complete ophthalmologic examination, including uncorrected distance visual acuity (UDVA), spectacle-corrected distance visual acuity (CDVA), manifest and cycloplegic refraction, slitlamp biomicroscopy, applanation tonometry, corneal topography, and ultrasonic pachymetry, and were deemed to be good candidates for corneal refractive surgery.

Humidity and temperature were checked every morning and recorded in a log book by a trained ophthalmic technician to the nearest whole percentage and degree Fahrenheit, respectively. The humidity and temperature were also logged for each patient in the excimer laser printout.

Excimer laser ablation for both LASIK and LASEK was performed using the Technolas 217z laser (Bausch \&
Lomb, Rochester, NY, USA). No nomogram adjustments were made for either LASIK or LASEK treatments. Surgeries were performed by four experienced surgeons, with surgical technique varying only slightly according to surgeon preference. All LASIK flaps were created using a 60-kHz femtosecond laser (IntraLase FS, Abbott Medical, Abbott Park, IL, USA), with a programmed flap thickness between 100 and $130 \mu \mathrm{m}$. Briefly, the flap was reflected, the stromal bed was dried, excimer laser ablation was immediately performed, and the flap was repositioned. The stroma was not washed before excimer laser ablation. If excimer laser treatment was briefly interrupted, it was resumed immediately without rinsing the stromal bed. Patients were prescribed ofloxacin $0.3 \%$ and prednisolone acetate $1 \%$ to be used four times per day for 1 week and then discontinued.

For LASEK, 20\% ethanol was applied to the central cornea using a circular well for $\sim 30$ seconds. The epithelium was removed as a single sheet in a circular pattern with a superior hinge. The stromal bed was dried, excimer laser treatment was performed, the epithelium was replaced, and a bandage contact lens was applied. Patients used ofloxacin and prednisolone acetate $1 \%$ eye drops four times per day for 1 week, with the steroid drop tapered at the discretion of the surgeon, typically over the course of 1 month.

Data extracted from the medical records of each patient included the intended refractive correction, and UDVA and CDVA with manifest refraction at 1 day, 1 week, 1 month, 3 months, 6 months, and 1 year postoperatively. The presence of DLK and need for refractive retreatment were recorded. The decision for retreatment was not made until refractive stability was obtained, at least 3 months postoperatively. No predetermined visual acuity criteria were used to determine necessity for retreatment. Rather, if the patient was dissatisfied with the UDVA and the surgeon deemed it possible to improve with additional treatment, the patient decided if he/she wished to undergo retreatment after discussion of the risks and benefits of the procedure.

Statistical analysis was performed using SAS 9.3 (SAS Campus Drive, Cary, NC, USA). Descriptive statistics of the sample were summarized with mean values and standard deviations (SDs) for continuous measures, and frequencies and percentages for categorical variables. Univariate linear mixed regression models were used to investigate the effect of temperature or humidity on both visual acuity and spherical equivalent outcomes. Repeated measures logistic regression models were used to investigate the effect of temperature or humidity on the probability of DLK or the probability of enhancement surgery. These models accounted 
for the correlation between eyes of a subject. Visual acuity was converted to $\log$ MAR equivalent for all analyses.

\section{Results}

A total of 863 eyes of 458 patients were included. Patient demographic and procedural data are included in Table 1. Patients were on an average 38.6 years old at the time of surgery and $53.1 \%$ were female. LASIK was performed on 676 eyes $(78.3 \%)$ of 358 patients and LASEK was performed on 187 eyes $(21.7 \%)$ of 100 patients. Average room temperature was $68.4^{\circ} \mathrm{F}(\mathrm{SD}=2.3)$ and ranged from $58^{\circ} \mathrm{F}$ to $76^{\circ} \mathrm{F}$; humidity was on an average $28.7 \%(\mathrm{SD}=14.4)$ and ranged from $10 \%$ to $72 \%$. Twenty-one eyes $(2.4 \%)$ underwent an additional refractive surgery (enhancement) for dissatisfaction with UDVA; only one of these eyes had undergone LASEK. DLK was noted in 76 eyes $(11.2 \%)$ that underwent LASIK.

Table 2 shows the results of models for the association between temperature and visual acuity. In eyes that underwent LASIK there were no significant associations between temperature and visual acuity (CDVA or UDVA) at any postoperative time point. Similarly, in eyes that underwent LASEK, temperature was not associated with UDVA. However, a small but statistically significant association was present between temperature and CDVA at the post-op day 1 visit only (estimate $-0.0274, P=0.001$ ). At all other time points there were no significant associations between temperature and visual acuity in eyes that underwent LASEK. Two eyes of one subject had LASIK surgery performed

Table I Patient demographic and procedural data for 863 eyes of 458 patients

\begin{tabular}{|c|c|}
\hline Variable & Value \\
\hline Age (years) & $38.6 \pm 10.3$ (range $2 \mid$ to 74$)$ \\
\hline Gender & $\begin{array}{l}\text { Female: } 243(53.1 \%), \\
\text { Male: } 215(46.9 \%)\end{array}$ \\
\hline Type of surgery & $\begin{array}{l}\text { LASIK: } 676 \text { (78.3\%), } \\
\text { LASEK: I } 87 \text { (2I.7\%) }\end{array}$ \\
\hline Treated spherical equivalent (D) & $\begin{array}{l}-3.80 \pm 2.03, \text { range } \\
(-10.33 \text { to }-0.25)\end{array}$ \\
\hline Follow-up (months) & $\begin{array}{l}3.8 \pm 4 . \mid \text { (range } \\
\text { I day to I year) }\end{array}$ \\
\hline Procedure room temperature $\left({ }^{\circ} \mathrm{F}\right)$ & $68.4 \pm 2.3$ (range 58 to 76$)$ \\
\hline Procedure room humidity (\%) & $28.7 \pm 14.4$ (range 10 to 72 ) \\
\hline UDVA at 3 months (logMAR) & $\begin{array}{l}0.00 \pm 0.14 \text { (Snellen } \\
\text { equivalent } 20 / 20 \text { ) }\end{array}$ \\
\hline CDVA at 3 months (logMAR) & $\begin{array}{l}-0.05 \pm 0.08 \text { (Snellen } \\
\text { equivalent } 20 / 18)\end{array}$ \\
\hline Enhancements & $21(2.4 \%)$ \\
\hline Diffuse lamellar keratitis (LASIK only) & $76(11.2 \%)$ \\
\hline
\end{tabular}

Note: Data represented as mean \pm standard deviation unless otherwise indicated. Abbreviations: CDVA, corrected distance visual acuity; D, diopters; LASEK, laserassisted keratomileusis; LASIK, laser in situ keratomileusis; UDVA, uncorrected distance visual acuity. outside the excimer laser manufacturer recommended limits for temperature $\left(76^{\circ} \mathrm{F}\left[24.4^{\circ} \mathrm{C}\right]\right.$, recommended range $18^{\circ} \mathrm{C}-24^{\circ} \mathrm{C}$ ). The patient had 20/20 UDVA on postoperative day 1 but was then lost to follow-up.

Table 3 shows the results of models for the association between humidity and visual acuity. In eyes that underwent LASIK, there were no significant associations found between humidity and UDVA. However, there were small but statistically significant associations between humidity and CDVA at the 1 day, 1 month, 3 months, and 1 year postoperative visits. Increases in humidity were associated with decreases (improvement) in logMAR CDVA. In eyes that underwent LASEK, humidity was not significantly associated with UDVA at any time point. There was a small but statistically significant association between higher humidity and better $\log$ MAR CDVA at the post-op month 1 visit, but this association was not present at any other time point. Four hundred sixty-six eyes (55.0\%) had surgery performed when humidity was outside the manufacturer recommended range of $30 \%-50 \%$ (range of humidity for treatment $10 \%-72 \%$ ). Of those, 449 (96.4\%) were below the recommendation and 17 (3.7\%) were above. Analysis using this three-way categorization (below, within, and above recommendation of humidity) did not show any significant associations with visual acuity at any time points in eyes that underwent LASIK or LASEK.

No significant associations were found between temperature or humidity and the postoperative manifest spherical equivalent refraction at any time point following surgery for both LASIK and LASEK $(P>0.05$ for all associations, data not shown).

Repeated measured logistic regression models did not demonstrate any significant associations between temperature and humidity and the need for enhancement or the incidence of DLK in eyes that underwent LASIK $(P>0.05$ for all associations, data not shown). In eyes that underwent LASEK, the relationship between environmental factors and enhancement could not be assessed, because only one eye underwent enhancement after LASEK.

\section{Discussion}

Our retrospective study does not support a clinically significant association between procedure room environmental variables and outcomes after excimer laser refractive surgery. Specifically, neither procedure room temperature nor humidity was significantly associated with postoperative UDVA or manifest spherical equivalent refraction in eyes that underwent myopic LASIK or LASEK. The need for enhancement and the incidence of DLK were also not significantly associated with the environmental variables studied. A small 
Table 2 Univariate linear mixed regression model results for the association of temperature with visual acuity

\begin{tabular}{|c|c|c|c|c|c|c|c|c|}
\hline \multirow[t]{3}{*}{ Outcome } & \multicolumn{4}{|l|}{ LASIK } & \multicolumn{4}{|l|}{ LASEK } \\
\hline & \multirow{2}{*}{$\begin{array}{l}\text { Estimate } \\
\text { (per } I^{\circ} \mathrm{F} \text { increase } \\
\text { in temperature) }\end{array}$} & \multicolumn{2}{|l|}{$95 \% \mathrm{Cl}$} & \multirow[t]{2}{*}{$P$-value } & \multirow{2}{*}{$\begin{array}{l}\text { Estimate } \\
\text { (per } I^{\circ} \mathrm{F} \text { increase } \\
\text { in temperature) }\end{array}$} & \multicolumn{2}{|l|}{$95 \% \mathrm{Cl}$} & \multirow[t]{2}{*}{$P$-value } \\
\hline & & Lower & $\overline{\text { Upper }}$ & & & Lower & $\overline{\text { Upper }}$ & \\
\hline \multicolumn{9}{|c|}{ IogMAR UDVA } \\
\hline PODI & -0.0039 & -0.0106 & 0.0028 & 0.255 & -0.0083 & -0.0318 & 0.0152 & 0.484 \\
\hline POWI & 0.0014 & -0.0042 & 0.0070 & 0.612 & -0.0039 & -0.0203 & 0.0125 & 0.634 \\
\hline POMI & -0.0005 & -0.0070 & 0.0059 & 0.873 & 0.0013 & -0.0118 & 0.0144 & 0.842 \\
\hline POM3 & -0.0005 & -0.0086 & 0.0075 & 0.895 & 0.0086 & -0.0084 & 0.0255 & 0.314 \\
\hline POM6 & -0.0014 & -0.0165 & 0.0138 & 0.858 & 0.0067 & -0.0084 & 0.0218 & 0.372 \\
\hline POYI & -0.0009 & -0.0116 & 0.0098 & 0.868 & 0.0040 & -0.0087 & 0.0167 & 0.512 \\
\hline \multicolumn{9}{|c|}{ logMAR CDVA } \\
\hline PODI & -0.0065 & -0.0163 & 0.0032 & 0.185 & -0.0274 & -0.0433 & -0.0116 & 0.001 \\
\hline POWI & -0.0019 & -0.0082 & 0.0044 & 0.554 & -0.0099 & -0.0331 & 0.0132 & 0.389 \\
\hline POMI & -0.0030 & -0.0094 & 0.0033 & 0.345 & -0.0102 & -0.0210 & 0.0007 & 0.065 \\
\hline POM3 & -0.0033 & -0.0104 & 0.0037 & 0.350 & -0.0048 & -0.0200 & 0.0104 & 0.515 \\
\hline POM6 & $-0.000 \mathrm{I}$ & -0.0085 & 0.0084 & 0.987 & $\begin{array}{l}\text { Not enough data } \\
\text { for model to run }\end{array}$ & & & \\
\hline POYI & 0.0006 & -0.0188 & 0.0201 & 0.946 & $\begin{array}{l}\text { Not enough data } \\
\text { for model to run }\end{array}$ & & & \\
\hline
\end{tabular}

Note: The value shown in bold reflects a $P$-value that is significant $(P<0.05)$.

Abbreviations: CDVA, corrected distance visual acuity; Cl, confidence interval; LASEK, laser-assisted keratomileusis; LASIK, laser in situ keratomileusis; PODI, postoperative day I; POWI, postoperative week I; POMI, postoperative month I; POM3, postoperative month 3; POM6, postoperative month 6; POYI, postoperative year I; UDVA, uncorrected distance visual acuity.

but likely clinically insignificant effect of humidity on CDVA after LASIK was observed. Overall, patients achieved excellent postoperative visual acuity and had a low enhancement rate, consistent with previously reported outcomes. ${ }^{1,2}$

Our findings support those of Seider et al who recently reported that in over 200,000 eyes, procedure room temperature and humidity did not have a clinically significant relationship with manifest refraction at 1 month after LASIK. ${ }^{10}$ Our results are also consistent with those of Randleman et al who reported that the need for enhancement was not associated with procedure room temperature and humidity in 853 eyes that underwent LASIK or

Table 3 Univariate linear mixed regression model results for the association of humidity with visual acuity

\begin{tabular}{|c|c|c|c|c|c|c|c|c|}
\hline \multirow[t]{3}{*}{ Outcome } & \multicolumn{4}{|l|}{ LASIK } & \multicolumn{4}{|l|}{ LASEK } \\
\hline & \multirow{2}{*}{$\begin{array}{l}\text { Estimate } \\
\text { (per I\% increase } \\
\text { in humidity) }\end{array}$} & \multicolumn{2}{|l|}{$95 \% \mathrm{Cl}$} & \multirow[t]{2}{*}{$P$-value } & \multirow{2}{*}{$\begin{array}{l}\text { Estimate } \\
\text { (per I\% increase } \\
\text { in humidity) }\end{array}$} & \multicolumn{2}{|l|}{$95 \% \mathrm{Cl}$} & \multirow[t]{2}{*}{$P$-value } \\
\hline & & Lower & Upper & & & Lower & Upper & \\
\hline \multicolumn{9}{|c|}{ logMAR UDVA } \\
\hline PODI & -0.0001 & -0.0012 & 0.0009 & 0.777 & -0.0006 & -0.0046 & 0.0035 & 0.782 \\
\hline POWI & -0.0005 & -0.0014 & 0.0004 & 0.246 & 0.0005 & -0.0024 & 0.0035 & $0.7 \mid 4$ \\
\hline POMI & -0.0005 & -0.0015 & 0.0006 & 0.371 & 0.0011 & -0.0012 & 0.0035 & 0.342 \\
\hline POM3 & -0.0002 & -0.0015 & 0.0011 & $0.74 I$ & 0.0001 & -0.0033 & 0.0034 & 0.974 \\
\hline POM6 & 0.0007 & -0.0022 & 0.0036 & 0.623 & 0.0010 & -0.0018 & 0.0037 & 0.472 \\
\hline POYI & -0.0005 & -0.0022 & 0.0012 & 0.535 & -0.0021 & -0.0049 & 0.0006 & 0.122 \\
\hline \multicolumn{9}{|c|}{ logMAR CDVA } \\
\hline PODI & -0.0014 & -0.0027 & 0.0000 & 0.046 & 0.0028 & -0.0013 & 0.0068 & 0.175 \\
\hline POWI & -0.0008 & -0.0016 & 0.0001 & 0.086 & 0.0000 & -0.0044 & 0.0044 & 0.992 \\
\hline POMI & -0.0011 & -0.0021 & -0.0001 & 0.034 & -0.0023 & $-0.004 I$ & -0.0005 & 0.015 \\
\hline POM3 & -0.0015 & -0.0026 & -0.0003 & 0.019 & 0.0009 & -0.0016 & 0.0034 & 0.472 \\
\hline POM6 & -0.0015 & -0.0038 & 0.0007 & 0.174 & $\begin{array}{l}\text { Not enough data } \\
\text { for model to run }\end{array}$ & & & \\
\hline POYI & -0.0030 & -0.0055 & -0.0006 & 0.020 & $\begin{array}{l}\text { Not enough data } \\
\text { for model to run }\end{array}$ & & & \\
\hline
\end{tabular}

Note: The values shown in bold reflect those $P$-values that are significant $(P<0.05)$.

Abbreviations: CDVA, corrected distance visual acuity; CI, confidence interval; LASEK, laser-assisted keratomileusis; LASIK, laser in situ keratomileusis; PODI, postoperative day I; POWI, postoperative week I; POMI, postoperative month I; POM3, postoperative month 3; POM6, postoperative month 6; POYI, postoperative year I; UDVA, uncorrected distance visual acuity. 
photorefractive keratectomy. ${ }^{9}$ The authors did not directly examine the association of environmental variables with visual acuity or refractive outcomes.

In contrast, two earlier studies suggested that environmental factors may play a role in refractive outcomes. In 237 eyes, de Souza et al demonstrated that lower procedure room temperature and humidity were significantly associated with a smaller spherical equivalent refraction after LASIK. ${ }^{7}$ In another retrospective study of 368 eyes, Walter and Stevenson reported that LASIK enhancement rates were associated with procedure room humidity in a multivariate model. ${ }^{8}$ Each $1 \%$ rise in humidity increased the odds for enhancement by $9.3 \%$. In addition, they demonstrated that an increase in room humidity was associated with a decrease in percentage of correction (under-correction). A recently published study of over 41,000 eyes found a small association between lower operating room temperature and retreatment rate (odds ratio $=1.15, P=0.04$ ) in a multivariate analysis. ${ }^{11}$ There was no significant association with humidity. However, the authors did not directly assess visual acuity or refractive outcomes.

It has been theorized that under-correction in excimer laser refractive surgery might occur in warm and humid environments, with over-correction in dry and colder ones, due to alterations in the hydration status of the cornea as well as effective laser fluence. Modeling has demonstrated that increased environmental temperature and humidity may absorb up to $32 \%$ of laser fluence and thus reduce the effective fluence applied to the corneal stroma. ${ }^{6}$ However, experimentally induced changes in temperature and humidity did not significantly alter laser energy fluence or myopic correction. ${ }^{12}$ The relative hydration of the cornea might also affect the depth of ablation achieved with each excimer laser pulse, with ablation expected to be deeper than intended in less hydrated corneas and more superficial in more hydrated corneas. Both preoperative and procedure room environmental parameters could affect relative corneal hydration. Although changes in humidity have been shown to affect the rate of aqueous tear evaporation,,$^{13}$ corneal thickness remains relatively stable despite large changes in humidity. ${ }^{14}$ However, in refractive surgery, exposure of the stromal bed to ambient room conditions before excimer laser ablation might influence corneal hydration. Authors have suggested that a nomogram be developed to account for the effects of environmental factors on laser ablation, ${ }^{8}$ but our findings do not support this recommendation. The current study not only looked at the enhancement rate, which is a surrogate measure of refractive accuracy, but also at the manifest spherical equivalent refraction across multiple follow-up visits. A clinically significant effect of procedure room environmental variables, if present, would be expected to be evident in postoperative refractive outcomes.

We found that the incidence of DLK, an infiltration of white blood cells between the flap and stromal bed following LASIK, was not associated with procedure room environmental variables. Although the etiology of DLK remains unclear, exogenous and patient factors are known to influence its occurrence. ${ }^{15}$ Our overall incidence of $11.2 \%$ (in LASIK eyes) was similar to another study from our institution ${ }^{15}$ $(12.4 \%)$ and is likely higher than other published reports because of the meticulous notation of the presence of even minimal inflammation in the flap interface; in that study only $2.7 \%$ of eyes required treatment beyond 1 week postoperatively with all DLK grade 2 or less. ${ }^{16} \mathrm{~A}$ higher rate of DLK would increase the power to detect an association between environmental variables and DLK, but our lack of finding such an association suggests that procedure room temperature and humidity do not contribute to its pathogenesis.

Our findings revealed a small but statistically significant association between procedure room humidity and logMAR CDVA after LASIK. At the 1 year postoperative visit, the estimate reflects that for each $1 \%$ increase in humidity, $\operatorname{logMAR}$ CDVA was decreased (improved) by 0.003 . In other words, each additional $6.7 \%$ increase in room humidity would result, on average, in one Early Treatment Diabetic Retinopathy Study letter of better CDVA. Given the small magnitude of effect, as well as the fact that there was no association between humidity and UDVA or manifest refraction, we do not have a reasonable potential mechanism for an association and therefore do not conclude that these findings represent causation. Further studies are needed to confirm the presence and degree of association between humidity and CDVA.

\section{Limitations}

Our study, by its retrospective design, has limitations. Although we had differential time of follow-up, most patients were followed for $>3$ months, at which point maximal visual acuity and refractive stability should be achieved. ${ }^{1,2} \mathrm{We}$ did not experimentally alter temperature and humidity and were thus limited by the ranges of these variables encountered in our clinical practice. However, the geographic location of our practice is such that we have a 4-season climate, with significant outdoor variation in temperature and humidity. Additionally, no cases were cancelled for variations from suggested environmental parameters, and thus our 
experience represents the ranges likely to be encountered in clinical practice. Only two eyes of one subject had surgery performed outside the manufacturer recommended limits for temperature, while the majority of eyes $(54.0 \%)$ had surgery performed outside the recommended range of $30 \%-50 \%$ humidity. This may have given us more power to detect an effect of humidity on visual outcomes, but no significant associations of humidity with UDVA or refraction were discovered. We did not have enough enhancements in the LASEK group to evaluate associations with environmental factors. The combined experience of four surgeons, with slight variations in technique, potentially increases the generalizability of our findings.

\section{Conclusion}

In summary, we did not find an association between procedure room temperature and humidity with UDVA, enhancement rate, incidence of DLK, or postoperative refraction in patients who underwent myopic LASIK or LASEK. Additional studies are needed to confirm our findings across other current excimer laser platforms.

\section{Disclosure}

The authors report no conflicts of interest in this work.

\section{References}

1. Schallhorn SC, Farjo AA, Huang D, et al. Wavefront-guided LASIK for the correction of primary myopia and astigmatism a report by the American academy of ophthalmology. Ophthalmology. 2008;115(7): 1249-1261.

2. Sugar A, Rapuano CJ, Culbertson WW, et al. Laser in situ keratomileusis for myopia and astigmatism: safety and efficacy: a report by the American academy of ophthalmology. Ophthalmology. 2002;109(1):175-187.

Clinical Ophthalmology

\section{Publish your work in this journal}

Clinical Ophthalmology is an international, peer-reviewed journal covering all subspecialties within ophthalmology. Key topics include: Optometry; Visual science; Pharmacology and drug therapy in eye diseases; Basic Sciences; Primary and Secondary eye care; Patient Safety and Quality of Care Improvements. This journal is indexed on Submit your manuscript here: http://www.dovepress.com/clinical-ophthalmology-journal
3. Ditzen K, Handzel A, Pieger S. Laser in situ keratomileusis nomogram development. J Refract Surg. 1999;15(2 Supp1):S197-S201.

4. Perlman EM, Reinert SE. Factors influencing the need for enhancement after laser in situ keratomileusis. J Refract Surg. 2004;20(6): 783-789.

5. Yang SH, Van Gelder RN, Pepose JS. Neural network computer program to determine photorefractive keratectomy nomograms. J Cataract Refract Surg. 1998;24(7):917-924.

6. Schena E, Silvestri S, Franzesi GT, Cupo G, Carito P, Ghinelli E. Theoretical model and design of a device to reduce the influence of environmental factors on refractive surgery outcomes. Conf Proc IEEE Eng Med Biol Soc. 2006;1:343-346.

7. de Souza IR, de Souza AP, de Queiroz AP, Figueiredo P, Jesus RS, kara-Jose N. Influence of temperature and humidity on laser in situ keratomileusis outcomes. J Refract Surg. 2001;17(2 Suppl):S202-S204.

8. Walter KA, Stevenson AW. Effect of environmental factors on myopic LASIK enhancement rates. J Cataract Refract Surg. 2004;30(4): 798-803.

9. Randleman JB, White AJ Jr, Lynn MJ, Hu MH, Stulting RD. Incidence, outcomes, and risk factors for retreatment after wavefrontoptimized ablations with PRK and LASIK. J Refract Surg. 2009;25(3): 273-276.

10. Seider MI, McLeod SD, Porco TC, Schallhorn SC. The effect of procedure room temperature and humidity on LASIK outcomes. Ophthalmology. 2013;120(11):2204-2208.

11. Mimouni M, Vainer I, Shapira Y, et al. Factors predicting the need for retreatment after laser refractive surgery. Cornea. 2016;35(5): 607-609.

12. Dantas PE, Martins CL, de Souza LB, Dantas MC. Do environmental factors influence excimer laser pulse fluence and efficacy? $J$ Refract Surg. 2007;23(3):307-309.

13. McCulley JP, Aronowicz JD, Uchiyama E, Shine WE, Butovich IA. Correlations in a change in aqueous tear evaporation with a change in relative humidity and the impact. Am J Ophthalmol. 2006;141(4): 758-760.

14. Cohen SR, Polse KA, Brand RJ, Mandell RB. Humidity effects on corneal hydration. Invest Ophthalmol Vis Sci. 1990;31(7):1282-1287.

15. Gritz DC. LASIK interface keratitis: epidemiology, diagnosis and care. Curr Opin Ophthalmol. 2011;22(4):251-255.

16. de Paula FH, Khairallah CG, Niziol LM, Musch DC, Shtein RM. Diffuse lamellar keratitis after laser in situ keratomileusis with femtosecond laser flap creation. J Cataract Refract Surg. 2012;38(6):1014-1019.
PubMed Central and CAS, and is the official journal of The Society of Clinical Ophthalmology (SCO). The manuscript management system is completely online and includes a very quick and fair peer-review system, which is all easy to use. Visit http://www.dovepress.com/ testimonials.php to read real quotes from published authors. 